\title{
Community-based health needs assessment in Léogâne and Gressier, Haiti: six years post-earthquake
}

\author{
Elizabeth A. Wood ${ }^{1 *}$, Kelly S. Chapman², Valery M. Beau de Rochars ${ }^{3}$ and Sarah L. Mckune ${ }^{1}$
}

\begin{abstract}
This article summarizes initial findings from a community-based health needs assessment designed to identify resources and gaps within the community and to prioritize community-identified health needs in Gressier and Léogâne, Haiti. From January to February of 2016, the University of Florida's College of Public Health and Health Professions (the College) conducted a community-based health needs assessment in collaboration with local community members, medical care providers, and NGOs. Data were collected using mixed-methods and community-participatory research in the form of 18 key informant interviews and 12 focus groups, consisting of between 4 and 11 individuals each, for a total of approximately 60 participants across all focus groups combined. Analysis yielded three key domains including concerns, barriers, and solutions to health and health care. The findings of this study create an overview of community-identified needs, which will be used to drive the College's agenda for future student work in the Gressier/Léogâne area of Haiti. Results also underscore the need to further investigate and understand the major health sub-domains.
\end{abstract}

Keywords: Haiti, Needs assessment, Community health

\section{Introduction}

In more recent years, Haiti has borne the brunt of seemingly insurmountable natural disasters, beginning with the 7.0 magnitude earthquake on January 12, 2010. The earthquake devastated the nation, leaving approximately 2.3 million people homeless, over 300,000 injured and more than 200,000 dead (United Nations 2012). Lack of health resources and access to care are especially prevalent in Haiti's rural areas where a mountainous environment, poor roads, and dependence on voodoo leaders result in additional challenges to health care provision (Urrutia et al. 2012). In 2013, there were approximately 25 physicians per 100,000 people, and approximately $40 \%$ of the people living in rural areas had no access to primary health care services (United Nations International Children's Emergency Fund 2013).

\footnotetext{
* Correspondence: liz07@phhp.ufl.edu

${ }^{1}$ Department of Environmental and Global Health, College of Public Health and Health Professions, University of Florida, 1225 Center Drive, P.O. Box 100182, Gainesville, FL 32610-0182, USA

Full list of author information is available at the end of the article
}

A major objective of this research is to identify and understand the current health concerns as prioritized by Haitians near the epicenter of the 2010 earthquake 6 years after the event. A community health needs assessment was necessary to define health needs and was used to determine which interventions should be implemented as a result (McKenzie et al. 2017). This process identifies priorities and evaluates which ones merit additional research, response, or intervention.

The catchment area for this study includes Léogâne and the neighboring area of Gressier, which are located approximately 20 miles west of the capital, Port-auPrince. Exact population figures are difficult to discern, for example, Gressier has a population of 36,453 according to the Haitian Institute of Statistics and Informatics (Institut Haïtien de Statistique et d'Informatique 2015); however, a local nongovernmental organization (NGO) and the Committee for the Advancement of Gressier, Haiti, report the population as high as 75,000 (Committee for the Advancement of Gressier, Haiti n.d. 2017). The city of Léogâne has a much larger population than Gressier, with a total of 199,813 in 2015 (Institut Haitien 
de Statistique et d'Informatique 2015). Between the two communities, there is little accessibility to clinics or hospitals that offer comprehensive health care.

According to Haiti's Ministry of Public Health and Population (MSPP), there are four public health clinics and two public hospitals in Gressier and one mixed (public and private) clinic and one MSPP clinic in Léogâne (Ministere de la Sante Publique et de la Population n.d. 2017). The number of NGOs and international organizations (IOs) in Haiti after the earthquake ranges from 3000 to 20,000 depending on the source, and information specifically for the Gressier and Léogâne region is unverifiable (Kristoff and Panerelli 2010; Schwartz 2008). There are currently 256 registered NGOs with the MSPP for all of Haiti; however, NGOs, IOs, and faith-based organizations that may also provide health care services are not required to register within Haiti (Ministere de la Sante Publique et de la Population n.d. 2017). The number of locally owned private facilities has largely remained unchanged since 2009 , though on average, the charge for medical treatment at private facilities has increased by $150 \%$ from 2009 to 2013 (Kligerman et al. 2015). Kligerman et al. (2015) speculate that a reduced number of patients using private clinics is responsible for the rate increase, thereby implying that the increase in foreign aid has resulted in a financial burden for existing local doctors and their remaining patients.

\section{Methods}

The University of Florida faculty and staff conducted a community health needs assessment, in partnership with Masters of Public Health students from the College of Public Health and Health Professions. Local translators and facilitators were recruited and hired from the Gressier and Léogâne community to assist in data collection and participant recruitment. The sample population included members of the community and key informants. Community members participated in focus group discussions, and key informant interviews included local officials and representatives from NGOs in the region. Fieldwork for this study was completed in January and February 2016. Using the Ecological Framework, this study generates a robust understanding of community perspectives on factors affecting the health of Haitians in the region, bringing the needs of the community into the forefront and creating a platform for participantdriven research. Community members and local stakeholders were given the space to discuss their concerns as they perceived them and encouraged to identify grassroots solutions to the problems they were most passionate about. At the conclusion of the focus groups and key informant interviews, major themes were compared and contrasted to identify major gaps and differences in perceptions of health care.

\section{Key informant interviews}

Key informant interviews were conducted in the respondent's native language (English, French, or Haitian Creole) by a native speaker. Interviews were semi-structured, and content included perceptions of community health needs, resources, barriers, and opportunities. A list of initial key informants was generated based on individual or organizational experience and knowledge of the community, and additional key informants were identified through snowball sampling. All participants were 18 years of age or older and had knowledge of local health concerns in Gressier and/or Léogâne.

A total of $18 \mathrm{key}$ informant interviews were conducted. This included seven staff and physicians from faith-based organizations, four representatives from NGOs, three academic personnel, two government employees, one private hospital, and one local business. Of the key informants, nine were females, seven were male, and two interviews included a male and a female. Eight of those interviewed were Haitian, nine were foreign (predominantly from the USA), and one interview had a Haitian and a foreign-born participant. Each key informant interview ranged from 30 to 60 min depending on availability. Informed consent was obtained prior to the interview.

Box 1 Key informant interview script, as it appears in English

\footnotetext{
Focus group instrument

1. What is the most important health issues facing residents of your community?

2. What resources are available to address these issues?

3. What actions are necessary to address these issues, and who is responsible for addressing these issues?

4. Which population needs the most help?

5. What are the barriers to improving this issue? What role do you play in improving the issue?
}

\section{Focus groups}

Twelve focus groups of variable size (range $=4-11$, mean $=7$, median $=7$ ) were conducted in targeted communities throughout Gressier and Léogâne. Local facilitators from the catchment area assisted in recruiting focus group participants based on specific criteria: age, gender, and location of residence. Focus groups were purposefully stratified by age $(18-24,25-$ 54 , and 55+) and gender (male and female) throughout the geographic target area. Each focus group was facilitated by one of the two Haitian facilitators, recruited and trained locally, who conducted the focus group in Haitian Creole and translated in real time. Members of the research team transcribed the group discussions in real time and were permitted to ask 
clarifying questions, which were translated by the community facilitators. The focus group discussions were recorded for full transcription and validation of original notes. Given the high rate of illiteracy within the focus group population, consent was given orally.

Investigators targeted focus group participants from both Gressier and Léogâne that represented varying socioeconomic levels. Local partners identified neighborhoods of differing socioeconomic status, then a local facilitator recruited focus group participants stratified by age range and/or gender. Monetary compensation was deemed culturally inappropriate by multiple local partners, but a small snack was offered during the focus group discussions in appreciation of participation. Focus group questions were modified, where necessary, based on data from key informant interviews and were piloted prior to the community health assessment with local participants. Twelve focus groups were conducted, ten with community members and two with medical students. Given the significant background of these two groups, findings from focus groups are presented for community members separate from medical students, as well as for all focus groups together.

Box 2 Focus group instrument, as it appears in English

\footnotetext{
Key informant instrument

1. How would you describe the major health concerns of Gressier and Léogâne?

2. Who are the major stakeholders involved in health in these areas?

Prompt: NGOs, Government, community groups, etc.

3. What resources are available to address health issues? (multiple levels)

Prompt: Has this evolved over time? Were others historically available?

4. What are the barriers (major or minor) to improving health in these areas? (multiple levels)

5. What are potential solutions?
}

\section{Findings}

Once all focus group and key informant interviews were transcribed, two researchers independently coded each transcript looking for key themes using a combination of qualitative content analysis as a research method and grounded theory as a theoretical framework. Themes were captured through a consensus after the two independent researchers presented their findings to the research team to ensure reliability. A total of three key domains emerged from key informant and focus group interviews, including concerns, barriers, and solutions to health and health care. Key domains were further coded with N-Vivo to uncover sub-domains of particular relevance to participants. Discussion of specific sub-domains was coded and given a value of 1 per interview, regardless of how many times that sub-domain arose during the interview. Some groups discussed a particular domain or sub-domain more extensively than others; however, extensive discussion does not necessarily indicate salience. For example, concerns of poor water quality may be unanimously agreed upon with little discussion, whereas a more controversial concern may elicit a longer discussion. In an attempt to reduce bias in determining overall relevance throughout the study population, the degree to which a sub-domain was discussed in each interview was not weighted differently, e.g., mentioning chronic illness once during an interview was given as much weight as a lengthy discussion.

\section{Concerns}

Analysis of key informant and focus group interviews identified three sub-domains identified as concerns faced by participant's communities. These sub-domains were pathogens, water, and regional destabilization (Table 1).

\section{Pathogens}

Pathogens discussed by both key informants and focus group participants included 14 general illnesses (such as diarrhea, rash, and tuberculosis), three sexually transmitted infections (HIV, syphilis, and general infections), four (predominantly) vector-borne diseases (malaria, dengue, chikungunya, and Zika), and one water-borne disease (cholera). Cholera was discussed most frequently as a pathogenic concern across the study population, mentioned by $28 \%(n=5)$ of key informants and $67 \%(n=8)$ of focus groups. One male participant stated, "I would not allow kids to go out to play in the water because of suspected cholera" while others also showed concern, especially among their children, about contracting cholera. Aside from cholera, key informants did not demonstrate a high degree of consensus on any other specific pathogenic concern. However, focus group interviews co-identified diarrhea, stomachache, cold/flu, malaria, Zika, fever, and vaginal infections as pathogens of concern to their communities.

\section{Water}

Water was discussed in the context of access, contamination, health effects, infrastructure, mosquito reservoirs, treatment strategies, and co-infections. Water was discussed specifically in the context of cholera in $25 \%$ ( $n=3$ ) of focus groups, but none of the key informant interviews. Lack of access to clean or purified water was mentioned in 20\% $(n=4)$ of key informant interviews and $83 \%(n=10)$ of focus groups, while water contamination was referenced by $15 \%(n=3)$ of key informants and $67 \%(n=8)$ of focus groups. Focus group participants identified sources of water contamination, 
Table 1 Major concerns discussed across sample population

\begin{tabular}{lllll}
\hline & Focus group data & & & Key \\
\cline { 2 - 4 } & Community members & Medical students & Focus group total & $\begin{array}{l}\text { informants } \\
n=18(\%)\end{array}$ \\
\hline Pathogens & $n=10(\%)$ & $2(100)$ & $11(92)$ & $11(61)$ \\
Water & $9(90)$ & $2(100)$ & $11(92)$ & $11(61)$ \\
Regional destabilization & $9(90)$ & 0 & 0 & $9(50)$ \\
Total & 0 & & $S D=6.35$ & $S D=1.15$ \\
\hline
\end{tabular}

such as trash being discarded into water sources (42\%, $n=5$ ) and water contamination as a result of soil leaching into well water $(25 \%, n=3)$ as concerns, whereas key informants did not discuss sources of water contamination.

Concerns focused on water-related activities, including improper hand/bathing hygiene, improperly cleaned water storage containers or water pump nozzles, toileting in water sources or on the land, and a lack of soap use. Thirty-five percent $(n=7)$ of key informants and $42 \%(n=5)$ of focus groups recommended more education on water treatment/purification and hygiene as a solution to issues of water contamination and vectorborne diseases stemming from stagnant water. Of the five focus groups to mention education as a solution, three also stated that education programs had previously visited their communities; however, the specifics of these educational programs were not elaborated. In 67\% $(n=8)$ of focus groups, one or more participants exhibited knowledge of hand washing and water purification techniques.

Participants mentioned water in relation to vaginal infections in two key informant interviews and in four focus groups, including participants with prior medical knowledge. Of the two key informants who discussed vaginal illness as a health concern, one participant stated a belief in a causal relationship between dirty water and vaginal illness, whereas the other key informant expressed a belief in an indirect relationship, specifically that wet underwear caused yeast infections. Details about how water might be directly responsible for vaginal infections was not discussed other than in the context of bathing in contaminated water. One medical student from the area stated, "Our water is not purified. The women have vaginal issues so it's mostly because of the water they use. Haiti is an underdeveloped country not everyone has the opportunity to have clean water. Most of the times it's contaminated." Other sources of vaginal infection, such as multiple sexual partners and urinating on the ground, were mentioned by one focus group.

\section{Regional destabilization}

The category regional destabilization included reductions in infrastructure, personnel, or resources to communities and was frequently discussed in the context of questioning the long-term sustainability of the influx of foreign aid following the 2010 earthquake. Specifically, destabilization included the closure of temporary aid clinics, the loss of international aid funding, reduced number of physicians to the area, and the inability to use or maintain equipment-such as water pumps installed by the Red Cross and donated medical equipment. While $78 \%(n=14)$ of key informants and 100\% $(n=12)$ of focus groups discussed a need for additional infrastructure, only key informants $(30 \%, n=9)$ discussed regional destabilization, specifically, as a concern facing communities.

\section{Barrier \\ Lack of infrastructure}

Lack of infrastructure was the most commonly identified barrier to health care and fell into three overarching categories: medical limitations, general infrastructure shortcomings, and recent reductions in resources. Medical barriers included a lack of trained professionals, inaccessibility to existing facilities, poor quality of care or facility, and a lack of equipment or supplies. Focus group participants, in comparison to key informants, discussed a lack of access to hospitals and clinics, which may speak to differences in defining "access" throughout the population or a bias in how access is measured by health care providers versus consumers.

\section{Quality}

Nearly half of key informants, on the other hand, discussed quality of care provided $(44 \%, n=8)$. In particular, one NGO clinic partner stated concern that " $50 \%$ of the medications are counterfeit. Even if you get it from the Dominican Republic, the medicine contents can include 50\% sugar and other materials and could potentially be harmful." Key informants discussed diagnostic limitations in terms of outdated or inaccessible equipment; however, focus group participants emphasized the length of time to receive diagnoses. Focus group participants did not discuss health care itself as being low quality; instead, low quality was defined as long distances, long wait times, and high-cost barriers. Focus group participants were more likely to associate free health care with higher quality, which may signify that pay-for- 
treatment services are simply inaccessible for the majority of participants.

\section{Government}

General infrastructure barriers to health care included ineffective/corrupt government, limited access to safe water, transportation, employment, education, electricity, and latrines. Corruption was discussed by $22 \%(n=4)$ of key informants and one focus group. Rather than view their government as corrupt, key informants (27\%, $n=5)$ and focus group participants $(58 \%, n=7)$ were more likely to discuss difficulty in gaining access to appropriate members of the government. For example, "Where do you find the congressman or government? No, we don't find them. No one talks to each other to have a solution." Key informants echoed these perceptions, "The government does not exist in Léogâne, almost like it is absent."

\section{Community engagement}

Focus group participants expressed dissatisfaction with current initiatives in their communities, "...many NGOs came but did not address the needs. In fact, they just came to do whatever they want and not what the community needs." A key informant in the region stated, "NGO's come with their own agenda instead of listening to the needs of the community and doing what the community needs." These examples demonstrate a level of dissatisfaction among key informants and focus group participants with government and organizations in charge, repeating a narrative within which community members are excluded from solutions and the distribution of goods and services.

\section{Existing resources}

Existing resources were discussed by key informants $(89 \%, n=16)$ and focus groups $(92 \%, n=11)$ and were generally mentioned in the context of solutions. However, the distribution of resources listed by key informants differed from that identified by focus group participants. Half of all key informants identified hospitals (50\%, $n=9$ ) as a resource, whereas focus group participants discussed hospitals in the context of a need in their communities, with 67\% $(n=8)$ arguing that the services should be provided at lower or no cost to patients. A focus group of young men stated, "So many times we have hospital, the person might have sickness but can't go because they can't afford to pay it." Relief agencies were discussed in the context of pulling out of Haiti in $94 \%(n=17)$ of key informant interviews and $92 \%(n=11)$ of focus groups.

Home remedies were identified as a solution in $58 \%$ ( $n=7$ ) of the focus groups, and when asked to define what "home remedies" referred to, six out of seven referred to the practice of boiling medicinal leaves in lieu of a prescription. Medicinal leaves were discussed as a last resort when medical treatment was otherwise unavailable or unaffordable. A group of elders said, "There is not nearby hospital. Around this area no one can help, so they have to buy leaves to treat themselves... sometimes we get better or worse." Some key informants $(11 \%, n=2)$, on the other hand, identified the lack of regulation on medication disbursement as a problematic practice in home remedy: "people can go to any pharmacy to buy medicine and they don't need a prescription for it."

\section{Solutions}

Key informants and community members held different opinions on recommended solutions to the aforementioned barriers. Figure 1 compares recommended solutions and related constraints across participant groups. Across the sample population, participants shared beliefs that more education is needed on water treatment methods and proper hygiene to reduce the spread of disease, and they both support incentivizing recent medical school graduates to return to their communities to promote health education and provide medical services. Additional recommended solution displayed less agreement between the two groups of informants. For example, key informants expressed the need for more participation among community members, whereas community members discussed a lack of opportunities to participate. While an evaluation of current efforts to promote community participation falls outside the scope of this publication, the different perceptions among opportunity providers and opportunity seekers demonstrate a barrier to collaborative partnerships between aid organizations and the communities they serve.

Additionally, key informants discussed the need to invest in community lead solutions yet did not demonstrate knowledge of community-level concerns or suggested solutions, which include investment in infrastructure, environmental maintenance, access to affordable health care services, microfinance, diet, and hygiene. Rather, key informants had a tendency to list organizational or top-down solutions, such as lack of medical supplies and low pharmaceutical quality. While both sets of concerns are warranted and arguably related, the differences in priorities between the two groups illustrate that neither the providers nor the recipients of services are completely aware of the barriers faced by the community at large.

Both groups articulated concerns regarding the sustainability of foreign aid as a constraint to recommended solutions. Key informants expressed concern that international aid is unsustainable because projects generally have a limited budget or finite duration, whereas focus groups identified concerns over the degree to which they are dependent on foreign aid. 


\begin{tabular}{|c|c|}
\hline \multicolumn{2}{|c|}{ Recommended Solutions and Related Constraints } \\
\hline Key Informants & Focus Groups \\
\hline Recommended Solutions: & Recommended Solutions: \\
\hline \multicolumn{2}{|c|}{$\begin{array}{l}\text { - Increase education on water treatment/purification and hygiene as a solution to issues of water contamination and vector borne } \\
\text { diseases stemming from stagnant water } \\
\text { - Increase incentives/requirements for medical students to return to their communities to promote education and health practices }\end{array}$} \\
\hline $\begin{array}{l}\text { - Increase participation among community members } \\
\text { - Increase the number of community health workers } \\
\text { - Increase government investment in local solutions } \\
\text { - Increase the supply of medical equipment to existing Haitian } \\
\text { doctors }\end{array}$ & $\begin{array}{l}\text { - Increase opportunities for collaborative partnerships } \\
\text { between community members and local NGOs } \\
\text { - Increase government investment in infrastructure } \\
\text { - Increase efforts to clean and maintain the environment } \\
\text { - Increase the number of high-quality free hospitals } \\
\text { - Increase microfinance opportunities } \\
\text { - Increase efforts to improve diet and hygiene }\end{array}$ \\
\hline $\begin{array}{l}\text { Constraints to Recommended Solutions: } \\
\text { - Concern that foreign aid is unsustainable and leaves } \\
\text { communities vulnerable once projects conclude or aid is } \\
\text { exhausted } \\
\text { - Concern that aid programs will reinforce unequal distribution of } \\
\text { power and resources among Haitian elites and national } \\
\text { governments }\end{array}$ & $\begin{array}{l}\text { Constraints to Recommended Solutions: } \\
\text { - Dependence on foreign aid in regions where ability to } \\
\text { produce local resources or capital is constrained } \\
\text { - Distrust of foreign aid providers due to a lack of fulfillment of } \\
\text { promises made to community members following the } 2010 \\
\text { earthquake, specifically the promise of increased } \\
\text { employment opportunities }\end{array}$ \\
\hline $\begin{array}{l}\text { 'On-going training and communication between and among } \\
\text { communities [is needed] so that the problems that actually exist on } \\
\text { the ground are teaching moments, rather than the knowledge transfer } \\
\text { that happen across health interests that are imposed from the } \\
\text { outside.' } \\
\text { 'Haitian people have too much of a reliance on outside help.' }\end{array}$ & $\begin{array}{l}\text { 'Every neighborhood should have a mediator and we should have } \\
\text { more sit downs about our problems and the way to go about fixing } \\
\text { them.' } \\
\text { 'There is a saying that if there are a lot of hands, the load is not } \\
\text { heavy. I believe if people come together to help, they can maintain } \\
\text { the water they have until more resources come up.' }\end{array}$ \\
\hline
\end{tabular}

Fig. 1 Recommended solutions and related constraints across key informant interviews and focus groups

Additionally, equitable distribution of resources was problematized across the sample population; however, key informants emphasized the distribution of goods and services, whereas focus groups expressed distrust related to unfulfilled promises for employment opportunities. These concerns emphasize the need for sustainable, grassroots solutions that aim to reduce dependence on foreign aid.

Overall, key informants tended to place the responsibility of action on the community members when discussing possible solutions: "Concerned citizens of the community need to do more when it comes to protecting the environment." In contrast, focus group participants were more likely overall to emphasize actions they were already underway and to suggest that programs and projects being conducted in their areas take a greater responsibility for improving the community. Based on these findings, there is a disconnect between key informants and community members in regard to constraints and recommended solutions.

\section{Discussion}

The community health needs assessment in Léogâne and Gressier reveals a need for improved understanding of how the different programs and interventions from various agencies in the region have impacted the local community as a whole. Communities are bigger than their individual parts; individual program evaluations may not be positioned to reflect the overarching needs and limitations of existing resources. Therefore, community level needs assessments such as this one demonstrate the ability for public health research to identify community-level gaps in access and care that exist across and between providers, rather than the outcome of single initiatives. By conducting needs assessments of both providers and consumers of health services, the results of this study indicate that providers of care may be overestimating community members' ability to access resources, such as medical facilities and clean drinking water.

Data from this study will be used to facilitate future projects and interventions, aimed at improving health outcomes and decreasing health disparities in the region. For example, $20 \%(n=4)$ of key informants and $83 \%$ $(n=10)$ of focus group participants shared a belief that poor water quality is an important health concern facing their communities. Furthermore, poor water quality was believed by some participants and key informants to be causally linked to vaginal illness. More information is needed to determine what people are defining as vaginal 
illness within the Gressier and Léogâne focus groups (i.e., the symptoms, and how people are interacting with water prior to experiencing these symptoms that may lead them to believe there is a relationship). However, this claim is supported by recent literature that found vaginal douching with unclean water has been associated with the human papillomavirus (HPV) (Bui et al. 2016). An additional study among a rural population in the Central Plateau of Haiti found that douching with various chemical and natural agents, almost always mixed with water, led to higher risks for sexual transmitted infections, HIV, and HPV (Seay et al. 2016). The Léogâne/Gressier areas are at an increased risk for cholera due to their proximity to a major highway (route 2 ), and both cities have faced several cholera outbreaks in the aftermath of hurricanes (Blackburn et al. 2014; Widmer et al. 2014).

Water, in general, emerged as a recurring theme in our research and was discussed in the context of contamination, disease risk, and accessibility. Since Gressier and Léogâne were the epicenters of the 2010 earthquake, this region experienced a high volume of NGOs and smaller faith-based organizations working independently on water, sanitation, and hygiene. As a result, further research is needed to determine the full scope of local health recommendations surrounding water and how such messaging is incorporated into the daily lives of community members. It is also worth investigating how effective these messages are at preventing disease and improving knowledge about water quality.

Focus group participants routinely expressed a need for high quality, free hospitals, and medical services in their communities. Since 2010, Haiti experienced an influx of emergency medical facilities and relief aid, and many of the emergency providers did not begin pulling out until 2013 to 2015. As a result, the current clinics and hospitals in the area no longer meet the community's expectations of what medical services should cost, if anything, as well as the comprehensiveness of the treatment. This prolonged accessibility of free, or low cost, western medical services offered by aid agencies appears to have shifted expectations about the cost of medical treatment while simultaneously reducing patronage to local Haitian doctors. This sudden departure of medical relief has also caused the local MSPP clinic to become inundated with more emergency patients. Consequently, staff and health care professionals are overworked and receive the same amount of resources despite having more patients, according to a key informant that works within the local MSPP. Additional research is needed to determine the current level of partnership and cooperation needed with local MSPP clinics from NGOs, IOs, or relief agencies that offer health care services.
Community members often expressed feeling excluded from participating in the planning or implementation of work being conducted by NGOs and faith-based organizations. Conversely, key informants discussed difficulty in establishing local buy-in and participation from community members. It should be noted that key informants and community members displaying different views and perspectives is not uncommon when conducting community-based participatory research (McKenna et al. 2011). Rather, these narratives indicate that community engagement is important to both the providers of services as well as the recipients. However, effective collaboration may require additional efforts or restructuring to strengthen and expand upon existing partnerships.

Due to the small sample size of this assessment, several limitations need to be considered. While the community member stratification was meant to be representative, those who chose to participate or were available to participate may not represent the full spectrum of health care beliefs. Focus group discussions were conducted in Haitian Creole and relied on Haitian facilitators to translate in real time; therefore, nuanced linguistic and/or cultural meanings may not have been fully represented. Subsequently, the findings are not generalizable outside of the region or to the study population as a whole; rather they indicate that such perceptions exist within the community at a particular point in time.

\section{Conclusions}

Following the 2010 earthquake, Haiti was overwhelmed with temporary aid and free medical services, with a higher than average population-to-NGO ratio in Léogâne and surrounding areas with highest earthquake activity (Schuller 2012). While medical services were vital in the initial aftermath following the earthquake, prolonged availability of free aid-based program and services greatly undermines existing infrastructure (Schwartz 2008). As medical aid and funding to Haiti has diminished over that past 6 years, it has left in its place a vacuum of health care practitioners and facilities (Kligerman et al. 2015). In turn, this has led to an increase in gaps in health care services such as obstetrics and emergency medicine. Local MSPP representatives shared this view and expressed frustration with the lack of coordination that relief agencies and health care-related NGOs have with the local or regional MSPP offices.

As a result of the key informant interviews and focus groups, investigators were able to determine the major health concerns, needs, and suggested solutions. Our findings indicate that key informants and community members often hold differing opinions on community health needs, existing resources, and possible solutions. By engaging with stakeholders and community members 
across socioeconomic status and level of prior medical experience, this research was able to identify areas of overlap and variation between individuals and organizations providing resources and their target communities. This research strengthened partnerships with local stakeholders by determining what local health resources and facilities are currently available within the communities and identifying gaps in health care access. Through these partnerships, we strive to create sustainable and culturally appropriate solutions that address health-related concerns voiced by participants.

\section{Acknowledgements}

This work was supported by the College of Public Health and Health Professions at the University of Florida. The authors thank the Christianville Foundation, the Haitian facilitators: Berlyne Bien-Aime and Judel Portain, the MPH student interns, and Dean Michael Perri of the College of Public Health and Health Professions for his continued support in Haiti.

\section{Funding}

Funding came from the University of Florida College of Public Health \& Health Profession Haiti Fund.

\section{Authors' contributions}

All authors have read and approved the manuscript and all authors have contributed equally to its development.

\section{Authors' information}

Elizabeth A Wood DHS, MPH (EAW) has carried out community health needs assessments since 2012 and worked in the Southern Peninsula of Haiti within the Ouest Department since 2015. Madsen Beau de Rochars MD, MPH (MBR) has extensive experience working in Haiti and is Haitian himself. In the dynamic to eliminate lymphatic filariasis (LF) in Haiti, he led the first mass drug administration (MDA) started in Léogâne Haiti; this pilot project served as a model for a scaling up a national MDA program throughout Haiti. He was instrumental in the success of implementing the Haitian national program; now, this program reaches all of Haiti for the first time, making elimination of LF an achievable goal.

\section{Competing interests}

The authors declare that they have no competing interests.

\section{Publisher's Note}

Springer Nature remains neutral with regard to jurisdictional claims in published maps and institutional affiliations.

\section{Author details}

${ }^{1}$ Department of Environmental and Global Health, College of Public Health and Health Professions, University of Florida, 1225 Center Drive, P.O. Box 100182, Gainesville, FL 32610-0182, USA. ²Department of Anthropology, University of Florida, Gainesville, FL 32610, USA. ${ }^{3}$ Department of Health Services, Research, Management, and Policy, College of Public Health and Health Professions, University of Florida, 1225 Center Drive, P.O. Box 100182 Gainesville, FL 32610-0182, USA.

Received: 28 July 2017 Accepted: 18 October 2017

Published online: 26 October 2017

\section{References}

Blackburn JK, Diamond U, Kracalik IT, Widmer J, Brown W, Morrissey BD et al (2014) Household-level spatiotemporal patterns of incidence of cholera, Haiti, 2011. Emerg Infect Dis 20(9):1516-1519. https://doi.org/10.3201/eid2009. 131882

Bui TC, Thai TN, Tran LT, Shete SS, Ramondetta LM, Basen-Engquist KM (2016) Association between vaginal douching and genital human papillomavirus infection among women in the United States. J Infect Dis 214(9):1370-1375. https://doi.org/10.1093/infdis/jiw388
Committee for the Advancement of Gressier, Haiti. (n.d.) (2017) Who we are. Retrieved from http://www.gressier.org/about.aspx

Institut Haïtien de Statistique et d'Informatique. (2015). Population totale, population de 18 ans et plus ménages et densités estimes en 2015. Retrieved from http://www.ihsi.ht/produit_demo_soc.htm

Kligerman M, Barry M, Walmer D, Bendavid E (2015) International aid and natural disasters: a pre- and post-earthquake longitudinal study of the healthcare infrastructure in Leogane, Haiti. Am Soc Trop Med Hyg 92(2):448-453

Kristoff, M., Panerelli, L. (2010) Haiti: a republic of NGOs? Retrieved from https:// www.usip.org/publications/2010/04/haiti-republic-ngos

McKenna SA, Iwasaki PG, Stewart T, Main D (2011) Key informants and community members in community-based participatory research: one is not like the other. Prog Community Health Partnersh 5(4):361-362

McKenzie JF, Neiger BL, Thackeray R (2017) Assessing needs. In: Planning, implementing, and evaluating health promotion programs, 7th edn. USA, Pearson Education, Inc

Ministere de la Sante Publique et de la Population. (n.d.) (2017) Cartographie Sanitaire D'Haiti. Retrieved from http://www.mspp.gouv.ht/cartographie/ index.php?valeur=2

Schuller M (2012) Killing with kindness: Haiti, international aid, and NGOs. London, Rutgers Univ Press

Schwartz T (2008) Travesty in Haiti: a true account of Christian missions, orphanages, food aid, fraud and drug trafficking. USA, Book Surge Publishing

Seay JS, Mandigo M, Kish J, Menard J, Marsh S, Kobetz E (2016) Intravaginal practices are associated with greater odds of high-risk HPV infection in Haitian women. Ethn Health 22(3):257-265. https://doi.org/10.1080/13557858. 2016.1246423

United Nations (2012) Haiti two years after the earthquake. Strategic Communications Division, UN Department of Public Information, New York, NY Retrieved from http://reliefweb.int/sites/reliefweb.int/files/resources/haiti_ two_years_after_DPI_factsheet_05012012.pdf

United Nations International Children's Emergency Fund. (2013) At a glance: Haiti. Retrieved from http://www.unicef.org/infobycountry/haiti_statistics.html

Urrutia R, Merisier D, Small M, Urrutia E, Tinfo N, Walmer DK (2012) Unmet health needs identified by Haitian women as priorities for attention: a qualitative study. Reprod Health Matters 20(39):93-103. https://doi.org/10.1016/s09688080(12)39602-x

Widmer JM, Ali A, Blackburn JK, Alam MT, Morris JG, Redden E et al (2014) Waterrelated infrastructure in a region of post-earthquake Haiti: high levels of fecal contamination and need for ongoing monitoring. Am J Trop Med Hyg 91(4): 790-797. https://doi.org/10.4269/ajtmh.14-0165

\section{Submit your manuscript to a SpringerOpen ${ }^{\mathcal{O}}$ journal and benefit from:}

- Convenient online submission

- Rigorous peer review

- Open access: articles freely available online

- High visibility within the field

- Retaining the copyright to your article

Submit your next manuscript at $>$ springeropen.com 